\title{
Infectivity of Human Olfactory Neurons to SARS-CoV-2: A Link to Anosmia
}

\author{
Omar Bagasra1* , Pratima Pandey${ }^{1}$, Jessica R. Sanamandra ${ }^{1}$, Jarrett M. Houston", \\ Ewen McLean ${ }^{2}$ and Helmut Albrecht ${ }^{3}$ \\ ${ }^{1}$ Claflin University, South Carolina Center for Biotechnology, SC, USA \\ ${ }^{2}$ Aqua Cognoscenti LLC, West Columbia, USA \\ ${ }^{3}$ Department of Internal Medicine, PRISMA Health Midlands, University of South Carolina, Columbia, SC, USA
}

\section{ARTICLE INFO \\ Article history: \\ Received: 26 March 2021 \\ Accepted: 26 July 2021}

\section{Online:}

DOI 10.5001/omj.2021.128

Keywords:

SARS-CoV-2; Anosmia;

Neurogenesis; Cell

Differentiation; Neurites;

Neuroblastoma; Serine

Proteases; Fluorescent

Antibody Technique.

\begin{abstract}
ABS TRACT
Objectives: We sought to determine whether SARS-CoV-2 infections are associated with anosmia and if this virus infects other neuronal cells. We utilized male and female olfactory neuronal cell lines and other olfactory cell lines to determine the viral targets. Methods: We used four undifferentiated and two partially differentiated human developing neuronal cell lines. Infectivity was confirmed by reverse transcription quantitative realtime polymerase chain reaction (RT-qPCR), immunofluorescence assay (IFA) probing with anti-SARS-CoV-2 antibody, evaluation of cytopathic effects, and neurite formation. We induced partial differentiation of all cell lines (since both olfactory cell lines were terminally differentiated) with retinoic acid (RA) to determine whether differentiation was a factor in viral permissiveness. The expression of serine protease, transmembrane serine protease 2 (TMPRSS2), and angiotensin-converting enzyme II (ACE2) receptors were examined by RT-qPCR and IFA to determine the mechanism of viral entry. Results: Four to five days after exposure, both olfactory cell lines exhibited morphological evidence of infection; IFA analyses indicated that $~ 30 \%$ of the neurons were SARS-CoV- 2 positive. At two weeks, $70-80 \%$ were positive for SARS-CoV-2 antigens. The partially differentiated (CRL-2266 and CRL-2267) and undifferentiated cell lines (CRL-2142, CRL-2149, CRL-127, and CDL-2271) were essentially non-permissive. After RA treatment, only CRL-127 exhibited slight permissiveness (RT-qPCR). The TMPRSS2 receptor showed high expression in olfactory neurons, but low expression in RA treated CRL-127. ACE2 exhibited high expression in olfactory neurons, whereas other cell lines showed low expression, including RA-treated cell lines. ACE2 expression slightly increased in CRL-127 post RA-treatment. Conclusions: Our studies confirm neurotropism of SARS$\mathrm{CoV}-2$ to olfactory neurons with viral entry likely mediated by TMPRSS2/ACE2. Other neuronal cell lines were non-permissive. Our results established that the nerve cells were infected regardless of male or female origin and strengthened the reported association of COVID-19 with loss of smell in infected individuals.
\end{abstract}

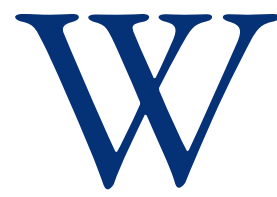

hen compared against the mortality rates estimated for the 1918-1920 H1N1 influenza A pandemic, the current deaths caused by COVID-19 are only slight. The so-called 'Spanish flu' pandemic, which came in three to four waves between March 1918 and February 1920, is estimated to have accounted for a low of around 18 million deaths, ${ }^{1}$ or $1 \%$ of the then global population, to a high of 100 million mortalities, ${ }^{2}$ or $5.6 \%$ of the population. In contrast, the present pandemic, caused by SARS-CoV-2, ${ }^{3}$ is presently credited with approximately 2.6 million deaths or about $0.3 \%$ of the global population. Nonetheless, the current public health emergency caused by SARS-CoV-2, has led many governments to institute strict quarantine measures to prevent its spread. Use of personal protective clothing, physical distancing, prohibition of gatherings, lockdowns, and curfews have become familiar policies to curtail viral infection rates and mortality.

Like the Spanish flu, the SARS-CoV-2 virus has been associated with a variety of symptoms including, but not limited to, acute respiratory distress syndrome (ARDS), which has been one of the major causes of death, ${ }^{4}$ dizziness and headache, sore throat, muscle fatigue and fever, nausea, diarrhea, and vomiting. ${ }^{5}$ Well-documented effects of $\mathrm{H} 1 \mathrm{~N} 1$ 
were inflammation of the optic nerve, blurred, and impaired color vision. ${ }^{6}$ Recent reports suggest that SARS-CoV-2 equally impacts the optic nerve. ${ }^{7}$ Another similarity between SARS-CoV-2 and H1N1 is its impact on taste and smell. Indeed, it appears that one of the earliest and more specific symptoms of SARS-CoV-2 infection is anosmia. In many cases, loss of smell and taste is noticed earlier than other symptoms, with patients otherwise remaining asymptomatic and recovering from the virus. ${ }^{8,9}$

Several possible causes underlying the development of anosmia during SARS-CoV-2 infection have been proposed. These include straightforward triggers, such as nasal blockage and rhinorrhea, perhaps coupled with olfactory cleft syndrome and cytokine release syndrome, through to disruption of olfactory receptor neurons (ORNs) and injury to olfactory perception centers in the brain. ${ }^{10,11}$ Here, we explore potential mechanisms of anosmia at the cellular and molecular levels using both male and female olfactory neuronal cell lines and four undifferentiated and two partially differentiated human developing neuronal cell lines. Since the olfactory system is unique among sensory systems (which are constantly going through neurogenesis) and its primary differentiated neurons bi-polar neurons come directly in contact with the external environment, we examine whether differentiation is a factor determining viral permissiveness. Of note, the olfactory bulb $(\mathrm{OB})$ is a six-layer structure in which the sequential stages of odor information processing occur. The axons on the cilia of ORNs in the nasal olfactory mucosa form the olfactory nerve layer of the OB. ${ }^{11}$ Secondary olfactory neurons, known as mitral cells (MCs) located in the mitral cell layer of $\mathrm{OB}$, and tufted cells (TCs) located in the external plexiform layer all innervate $\mathrm{OB}$ glomeruli. In addition, a large number of granule axon-less interneurons are located in the most central cell layer of the OB. The apical dendrites of granule cells form synapses with MCs and TCs. The expression of serine protease, transmembrane serine protease 2 (TMPRSS2), and angiotensin-converting enzyme II (ACE2) receptors were also examined to evaluate potential mechanisms of viral entry.

\section{METHODS}

Six undifferentiated human neuroblastoma (NB) cell lines were purchased from ATCC (New York, NY).
CRL-2267, CCL-127, CRL-2271 (of male origin) CRL-2266, and CRL-2149, (of female origin) were cultured in Eagle's minimum essential media (EMEM) (ATCC, Manassas, VA) supplemented with $10 \%$ heat-inactivated fetal bovine serum (FBS), and L-glutamine-penicillin-streptomycin solution (designated complete media) (Sigma, St. Louis, $\mathrm{MO}$ ) at $37{ }^{\circ} \mathrm{C}, 5 \% \mathrm{CO}_{2}$. Two olfactory $\mathrm{NB}$ cell lines, TC-268 and JFEN, of female and male origin, respectively, were gifted from Timothy J. Triche (Department of Pathology, Children's Hospital of Los Angeles, Los Angeles, CA 90027). The stock cell cultures were grown in $25 \mathrm{~mL}$ or $75 \mathrm{~mL}$ flasks (Thermo-Scientific, Nunc, Rochester, NY). Three SARS-CoV-2 isolates were collected from confirmed SARS-CoV-2 infected individuals; one isolate was used for the initial studies. ${ }^{12}$ HT29mer, a colon epithelial cell line (William G. Thilly, Biological Engineering, MIT) was used as a negative control.

Each of the three SARS-CoV-2 samples were propagated in Vero cells (ATCC). The cells were grown in EMEM at $80 \%$ confluency in $25 \mathrm{~mL}$ tissue culture flasks (Nunc Inc., USA). After removing the culture media, the viral inoculum was added to give a multiplicity of infection (MOI) of 0.1 to $0.05 /$ cell. Flasks were incubated at $37^{\circ} \mathrm{C}, 5 \% \mathrm{CO}_{2}$, with gentle agitation for two hours. After incubation, the unattached virions were removed by gentle washing with $5 \mathrm{~mL}$ phosphate buffered saline (PBS) and then $5 \mathrm{~mL}$ of complete media was added, and the cells were maintained for five days. Cells were trypsinized and cryopreserved in $1 \mathrm{~mL}$ vials in $50 \% \mathrm{FBS}$ and $10 \%$ DMSO at $-80^{\circ} \mathrm{C}$ and used in subsequent studies. ${ }^{12}$

To examine the permissiveness of $\mathrm{NB}$ cell lines to SARS-CoV-2, all six undifferentiated cell lines and two olfactory NB cell lines, TC-268 and JFEN ${ }^{12}$, were either grown in $25 \mathrm{~mL}$ tissue culture flasks or 8 -well chamber slides (Thermo Scientific, Nunc, Rochester, NY) to $~ 60 \%$ confluency. The media was removed and cells immediately exposed to an MOI of $0.1-0.05$ in $1.0 \mathrm{~mL}$ serum-free media. For maximum infectivity, the flasks were intermittently gently agitated for two hours, washed once in $5 \mathrm{~mL}$ PBS and then $5 \mathrm{~mL}$ of pre-warmed media was added. Control cultures were treated identically, except no SARSCoV-2 was added to the 8 -well chambers. The cells were incubated at $37^{\circ} \mathrm{C}, 5 \% \mathrm{CO}_{2}$. The cell cultures remained in the 8-well chambers for five days, and then the supernatants were carefully removed, and cells fixed in $2 \%$ fresh paraformaldehyde (PFA) and 
the slides were subsequently incubated under UVlight overnight in a SterilGard ${ }^{\circ}$ BLS-2 hood (Baker Company). These slides were used to carry out immunofluorescence assay (IFA) analyses. A separate set was stained with hematoxylin and eosin (H\&E) (Leica Biosystems Richmond, Inc., Richmond, IL) for morphological studies and images recorded using a digital camera (Olympus BX51). Each experiment was repeated at least three times. All experiments were carried out in a high containment laboratory according to the Centers for Disease Control and Prevention (CDC) guidelines for COVID-19 handling, and all biosafety measures were taken to avoid the viral infection. ${ }^{13}$

For immunocytochemical studies, each cell line was grown in 8 -well chamber slides with $\sim 1 \times 10^{5}$ cells in $0.3 \mu \mathrm{L}$ of media for five days. For seeding the $\mathrm{NB}$ cell lines, the stock cell cultures, grown in flasks, were gently washed once with $1 \times$ sterile PBS (Fisher Scientific, Fair Lawn, NJ), followed by trypsinization, until single cell suspension and inactivation of trypsin with $1 \mathrm{~mL}$ FBS. The cells were counted using a hemocytometer chamber and adjusted to $1 \times 10^{5}$ cells $/ \mathrm{mL}$. The 8 -well chamber slides were labeled, and $100 \mu \mathrm{L}$ of cells added to each well together with $5 \mu \mathrm{L}$ of fresh media containing $0.1-0.05 \mathrm{MOI}$ of the virus. After two hours incubation, the cells were washed gently with pre-warmed PBS, and $500 \mu \mathrm{L}$ of fresh media was added. After five days culture, the media was removed from the slides, and the cells were fixed by adding $800 \mu \mathrm{L}$ of $2 \%$ PFA to each well and allowed to set overnight at room temperature, under an UV-light in a SterilGard Hood. The wells were then washed gently three times using $1 \mathrm{x}$ sterile PBS and then soaked with the blocking agent (containing $2 \%$ bovine serum albumin (BSA) in $1 \times \mathrm{PBS}$ ) for 10 minutes. SARS-CoV-2 was detected by utilizing polyclonal nucleoprotein antibody to SARS-CoV-2 raised in rabbit (Cat \#PA5-81794, Thermo-Fisher Scientific). All antibody dilutions were carried out in $2 \% \mathrm{BSA}$ in $1 \times \mathrm{PBS}$. The primary antibody $(\mathrm{Ab})$ was diluted to 1:100 in blocking buffer. In each well, 100 $\mu \mathrm{L}$ of diluted primary $\mathrm{Ab}$ was added. The slides were incubated at $4{ }^{\circ} \mathrm{C}$ overnight in a humidified chamber and then washed three times in $1 \times$ PBS. Then, goat anti-rabbit fluorescein conjugated secondary $\mathrm{Ab}$ was used at a working dilution of $1: 40$ with $100 \mu \mathrm{L}$ in each well. The slides were incubated for one hour at $37^{\circ} \mathrm{C}$ in humidified chambers and then washed three times with PBS with 10 minutes incubation each time. The tops of the 8 -well chamber were removed with a device provided by the manufacturer without disturbing the fixed cells. The cells were washed in PBS three times and then mounted with glass coverslips using a drop of mounting solution containing 50\% glycerol and 50\% PBS. The slides were observed at resolutions of $\times 10, \times 40$, and $\times$ 1000 (with oil) using an Olympus BX51 fluorescent microscope. Each experiment was repeated at least three times. The slides were analyzed independently in a blind fashion by two observers.

For morphological studies, each cell line was grown in 8-well glass chamber slides with $1 \times 10^{5}$ cells in $100 \mathrm{~mL}$ of media for five days, as described above. After five days, the media was removed from the slides, and the cells were fixed by adding $500 \mu \mathrm{L}$ of freshly prepared 2\% PFA to each well and allowed to incubate overnight at room temperature. The caskets of the glass slides were removed, and the slides were washed gently three times using PBS. These slides were stained with freshly prepared $\mathrm{H} \& \mathrm{E}$, washed in distilled water for one minute, and mounted with the mounting buffer containing 50\% PBS and 50\% glycerol. These slides were observed under $\times 10$ and $\times 40$ magnification and analyzed for neurite formation (i.e., central chromatolysis, axonal length, thickness, thinning, and degeneration). Additionally, syncytia formation and other morphological and cytotoxic changes were recorded for comparison to controls. The experiments were repeated at least three times, and the observations were recorded using a digital camera (Olympus BX51).

The SARS-CoV-2 RNA copies were quantified using one-step reverse transcription polymerase chain reaction (RT-PCR). Viral RNA was extracted from culture pellets using GenElute ${ }^{\mathrm{mt}}$ Mammalian Total RNA Miniprep kit (Sigma, St. Louis, MO) according to the manufacturer's protocol. Two sets of primer pairs were designed to target the nucleocapsid region of the virus genome, according to CDC published primers (https://www.cdc.gov/coronavirus/2019ncov/lab/rt-pcr-panel-primer-probes.html). The list of the primers for SARS-CoV-2, TMPRSS2 and ACE2 expression are listed in Table 1. The reactions of quantitative real-time PCR (RT-qPCR) were carried out using an iScript One-step RT-PCR kit with SYBR Green (Bio-Rad, Hercules, CA), and quantification was performed using an ABI 7500 realtime cycler (Applied Biosystems, Foster City, CA). The thermal cycling profile of this assay consisted 
Table 1: Forward and reverse primer sequences used.

\begin{tabular}{|c|c|c|}
\hline Primers & & Sequences \\
\hline \multicolumn{3}{|c|}{ TMPRSS2_Primers } \\
\hline \multirow[t]{2}{*}{ Primer 1} & F: & 5’-CAAGATGAGCCCACGCGTCCCTCAGCAGGATTG-3’ \\
\hline & $\mathrm{R}:$ & 5' ССТСТTCСACATTTGACTTCAGATGATGTTGATAAAG-3 \\
\hline \multicolumn{3}{|c|}{ SARS-CoV-2_Primers } \\
\hline \multirow[t]{2}{*}{ Primer 1} & F: & 5'-TTACAACATTGGCCGCAAA-3' \\
\hline & $\mathrm{R}:$ & 5'-GCGCGACATTCCGAAGAA-3' \\
\hline \multirow[t]{2}{*}{ Primer 2} & F: & 5’-GGGAGCCTTGAATAGCAGCATTG-3' \\
\hline & $\mathrm{R}:$ & 5'-TGTAGCACGATTGCAGCATTG-3' \\
\hline \multicolumn{3}{|c|}{ ACE2 Primers } \\
\hline \multirow[t]{2}{*}{ Primer 1} & F: & 5’-GGGATCAGAGATCGGAAGAAGAAA-3' \\
\hline & $\mathrm{R}:$ & 3’-AGGAGGTCTGAACATCATCAGTG-5’ \\
\hline \multirow[t]{2}{*}{ Primer 2} & F: & 5’-AAACATACTGTGACCCCGCAT-3' \\
\hline & R: & 3'-CCAAGCCTCAGCATATTGAACA-5' \\
\hline \multirow[t]{2}{*}{ Primer 3} & F: & 5'-TCCAGACTCCGATCATCAAGC-3' \\
\hline & $\mathrm{R}:$ & 3’-GCTCATGGTGTTCAGAATTGTGT-5' \\
\hline
\end{tabular}

TMPRSS2: transmembrane serine protease 2; ACE2: angiotensin-converting enzyme II.

of a 15 minute cDNA synthesis step at $50{ }^{\circ} \mathrm{C}, 5$ minutes of iScript reverse transcriptase inactivation at $95^{\circ} \mathrm{C}$, followed by 40 cycles of PCR at $95^{\circ} \mathrm{C}$ for 10 seconds and a step of a single fluorescence emission data collection at $55^{\circ} \mathrm{C}$ for 30 seconds. Each experiment was repeated three times. Results were analyzed using HID Real-Time PCR Analysis Software v1.2 (Thermo Scientific, Waltham, MA). The relative degree of SARS-CoV-2 replications in different cell lines was calculated using cycle threshold values.

\section{RESULTS}

A presence/absence assay was conducted by RTqPCR to determine the permissiveness of SARS$\mathrm{CoV}-2$ infection in various cell lines. Analysis for the presence of SARS-CoV-2 showed positive infection of olfactory cell lines only [Figure 1]. The six undifferentiated human developing brain cell lines showed negative results [Table 2]. The same uninfected cell lines were used as controls, which showed an absence of SARS-CoV-2 RNA [Table 2]. Similar to the controls, cell lines CRL-2266, CRL2267, CRL-2271, CRL-2142, and CCL-127 were negative for SARS-CoV-2 infection as determined by RT-qPCR. There were no differences in the degree of the permissiveness of SARS-CoV-2 between NB cell lines of male and female origin [Table 2]. An immunofluorescence assay (IFA) with polyclonal nucleoprotein antibody to SARS-CoV-2 confirmed the RT-qPCR results [Table 2 and Figure 1]. All eight cell lines were exposed to retinoic acid (RA) at $1 \mathrm{mg} /$ $\mathrm{mL}$ for 48 hours to induce partial differentiation and exposed to SARS-CoV-2. After 48 hours of exposure to RA TC-268, JFEN and CRL-127 exhibited RAinduced cytotoxicity resulting in neuronal death and dysregulation in neurite formation (chromatolysis, elongation of axon, appearance of axon outside of axonal hillocks, and appearance of multiple axons). CRL-127 exhibited a low degree of permissiveness to the virus as determined by IFA and RT-qPCR. Other cell lines (CRL-2266, CRL-2267, CRL2142, CRL-2149, and CRL-2271) were partially differentiated via 48 hour RA exposure. However, RA exposure did not result in permissiveness to the virus in any cell lines as determined by RT-qPCR and IFA. The most prominent partial differentiation was observed in CRL-2266 and CRL-2267 where $31 \%$ and $22 \%$ of the neurons developed long axons, and the neurons became highly elongated. However, neither of the cell lines became permissive to SARS$\mathrm{CoV}-2$. The presence or absence of SARS-CoV-2 in all the cell lines was further confirmed by utilizing two sets of primer pairs by RT-qPCR and IFA. Both CRL-2142 and CRL-2149 exhibited a low degree of non-specific binding. HT29mer (ATCC HTB-38) was negative for SARS-CoV-2.

The permissiveness of all eight cell lines was further explored by determining the expression 

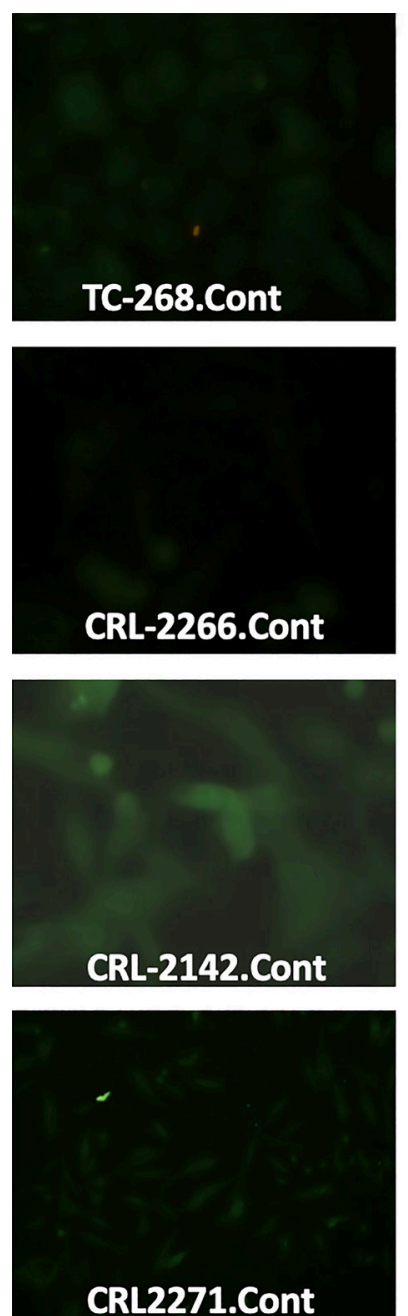

Cont
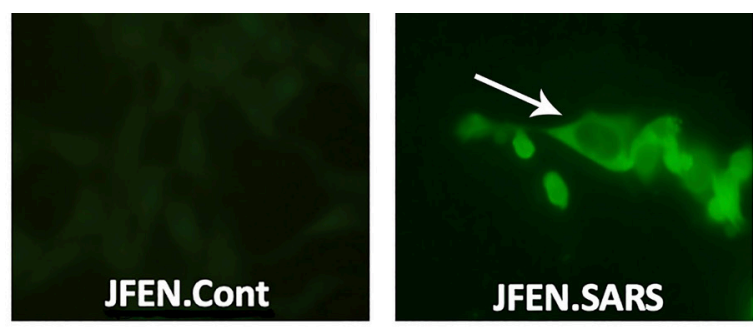

TC-268.SARS
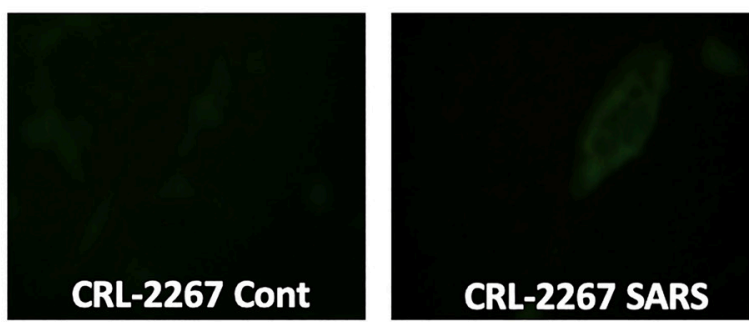

CRL-2266. SARS
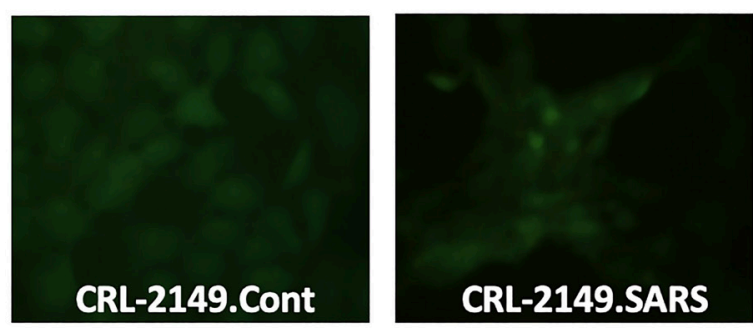

CRL-2142.SARS
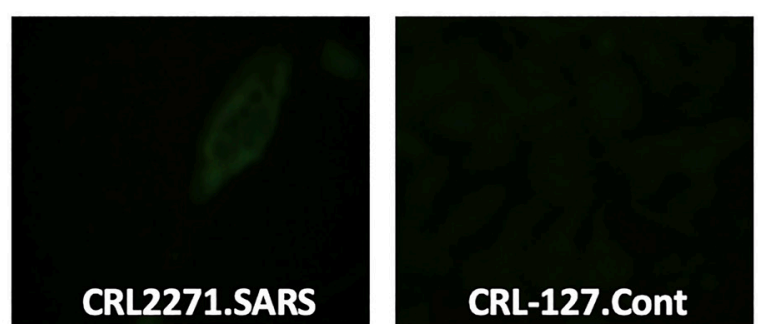

Figure 1: Immunofluorescence assay using a polyclonal antibody to SARS-CoV-2 nucleoprotein antigens to detect SARS-CoV-2 antigen expression on the cell surface of SARS-CoV-2 infected and uninfected neuroblastoma cell lines. (Top row, left to right): TC-268 uninfected; TC-268 SARS-CoV-2 infected; JFEN uninfected; JFEN SARS-CoV-2 infected, (Second row, left to right): CRL-2266 uninfected; CRL2266 SARS-CoV-2 infected; CRL-2267 uninfected; CRL-2267 SARS-CoV-2 infected, (Third row, left to right): CRL-2142 uninfected; CRL-2142 SARS-CoV-2 infected; CRL-2149 uninfected; CRL-2149 SARSCoV-2 infected, and (Bottom row, left to right): CRL-2271 uninfected; CRL-2271 SARS-CoV-2 infected; CRL-127 uninfected; CRL-127- SARS-CoV-2 infected. Magnification $=40 \times$.

of TMPRSS2 and ACE2 receptors. As shown in Table 2, the high permissiveness of TC-268 and JFEN correlated with the high expression of TMPRSS2 and ACE2 receptors. Both olfactory cell lines demonstrated a relatively high degree of TMPRSS2 and ACE2 expression, whereas the other cells showed negative expression of the TMPRSS2 receptor, except for CRL-127. After RA-induced differentiation, only CRL-127 exhibited low expression of TMPRSS2, which correlated with RT-qPCR and IFA observations [Figure 1 and 2]. RT-PCR for ACE2 receptors exhibited very low expression in all non-olfactory neuronal cell lines. Except for JFEN and TC-269 cell lines, none of the other cell lines were permissive to the virus. Only partially differentiated CRL-127 exhibited permissiveness, which correlated with the higher expression of TMPRSS2 and ACE2 receptors.

All human developing neuronal cell lines, infected as well as uninfected controls, were observed daily post-infection. Cytopathic effects (CPEs) were discernable within 72 hours postinfection in TC-268 and JFEN, when the neurons began to exhibit clustering foci on the monolayers. The numbers of foci increased on days four and five. On the upper surface of the foci, rounded cells appeared that formed syncytia-like structures; these were dead cells. The CPE was more prominent in the 
Table 2: Percentage of SARS-CoV-2-infected olfactory neurons and other human developing neurons as determined by immunofluorescence assay (IFA) and confirmed by reverse transcription polymerase chain reaction (RT-PCR).

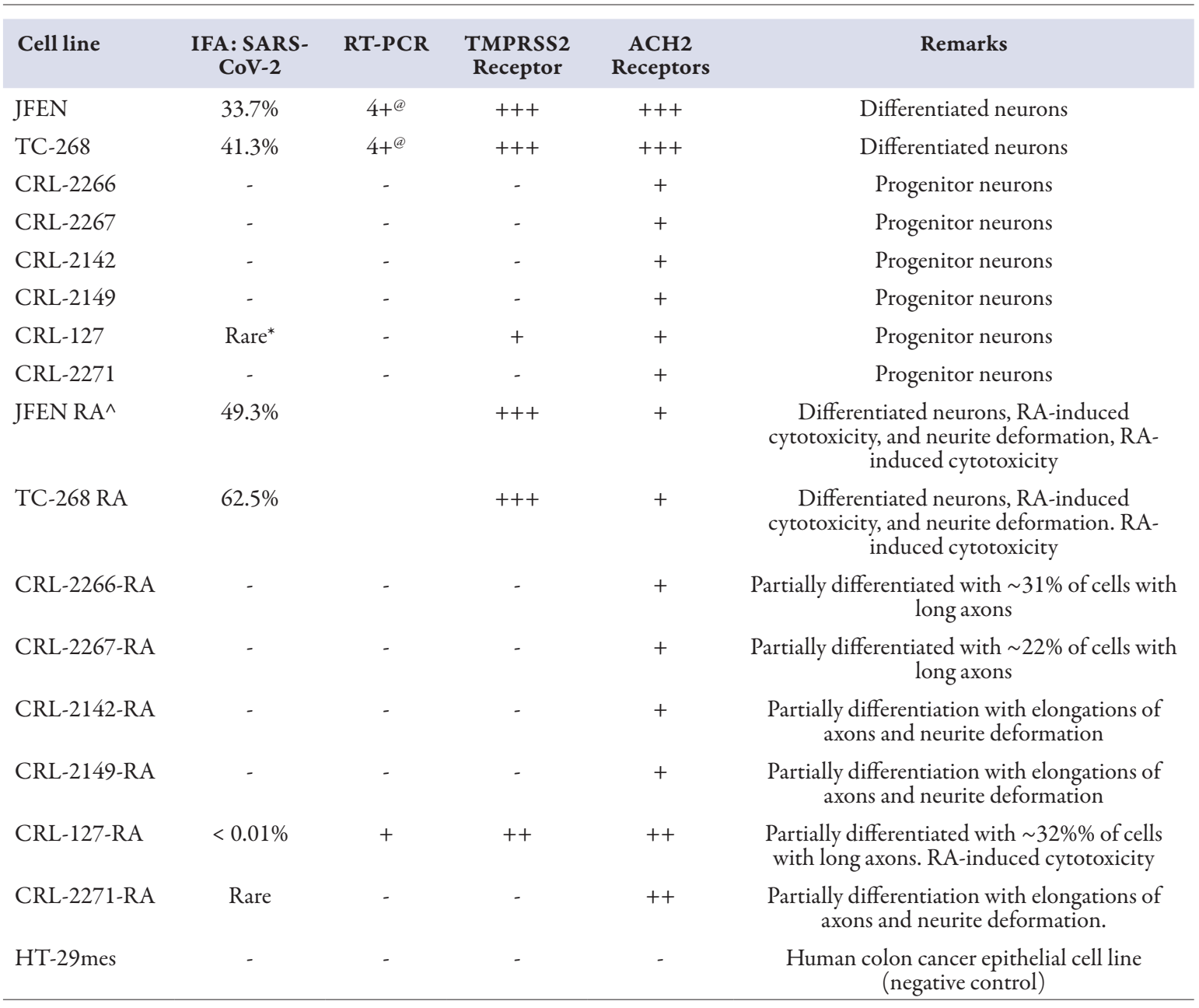

TMPRSS2: transmembrane serine protease 2; ACE2: angiotensin-converting enzyme II.

$4+$ is designated when the amplification line on the gel band is very bright.

${ }^{\wedge}$ Treatment with retinoic acid $(1 \mu \mathrm{g} / \mathrm{mL})$ for 48 hours.

${ }^{*}$ Rare is designated when the band on the gel is negative, similar to a negative control, but IFA shows rare ( 1:1000) cells exhibit cytoplasmic positive cells for SARSCoV-2 spike antigen. There were no apparent morphological changes, and no clear neurite deformation can be discerned between the controls and the infected cell lines.

TC-268 cell line when compared to JFEN. JFEN showed rapid thinning of the monolayer instead of CPE, and infection with SARS-COV-2 produced acute lytic effects in JFEN rather than the CPE described for the TC-268. Both infected cell lines also exhibited neurite deformations, exhibiting highly abnormal morphology, including neurons showing elongation of cells, vacuolation within the cytoplasm, enlargement of the neuronal cell body, shortening, thinning or abnormal increase in axonal length, change in cellular diameter, and central chromatolysis, and other aberrant cellular morphology [Figure 2]. None of the other six cell lines showed any morphologic changes and appeared to be non-permissive to the CPEs of SARS-CoV-2.
Therefore, even 12 weeks post-infection, the cells grew at a similar rate to uninfected cells. However, RA induced noticeable morphologic changes to all eight cell lines. RA induced immediate CPE in TC-268 and JFEN and stimulated the process of differentiation in the rest of the nonpermissive cell lines, with elongations of axonal length as well as elongations of neurons. CRL127 exhibited amplification of neuronal vacuoles and the development of unusually large neurons. CRL-127 was the only cell line that became permissive to SARS-CoV-2 [Table 1 and Figure 2]. Immunostaining with SARS-CoV-2 $\mathrm{Ab}$, as well as RT-qPCR, confirmed the relative permissiveness of CRL-127 to SARS-CoV-2 [Table 1 and Figure 2]. In 

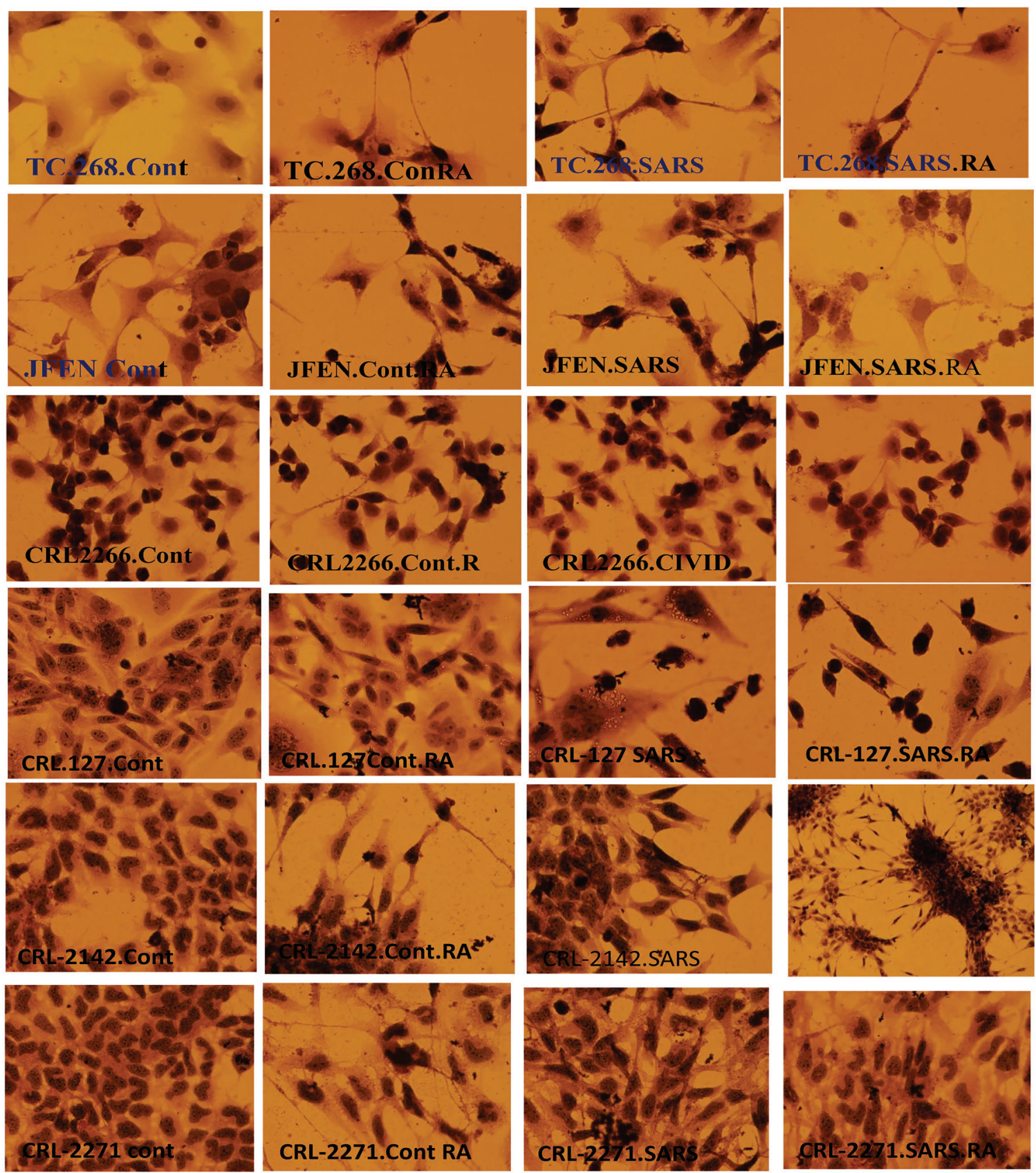

Figure 2: Morphological analyses using H\&E staining. (Top row, left to right): TC-268 uninfected; TC268 SARS-CoV-2 infected; TC-268 uninfected RA; TC-268 SARS-CoV-2 infected RA, (Second row, left to right) JFEN uninfected; JFEN SARS-CoV-2 infected; JFEN uninfected RA; JFEN SARS-CoV-2 infected RA, (Third row, left to right) CRL-2266 uninfected; CRL-2266 SARS-CoV-2 infected; CRL-2266 uninfected CRL-2267 uninfected RA; CRL-2267 SARS-CoV-2 infected RA, (Fourth row, left to right) CRL-127 uninfected; CRL-127- SARS-CoV-2 infected; CRL-127 uninfected RA; CRL-127-SARS-CoV-2 infected RA, (Fifth row, left to right) CRL-2142 uninfected; CRL-2142 uninfected; CRL-2142 uninfected RA; CRL-2142 SARS-CoV-2 infected RA, and (Sixth row, left to right) CRL-2271 uninfected; CRL-2271 uninfected RA; CRL-2271; CRL-2271 SARS-CoV-2 infected; CRL-2271 SARS-CoV-2 RA. Magnification = $40 \times$.

addition, after RA-treatment, CRL-127 was positive for the TMPRS22 receptor.

In summary, RA-treatment induced partial differentiation in all six non-permissive cell lines, and CRL-127 became permissive to SARS-CoV-2 infection. RA also induced marked and significant changes in neurons and caused neurite deformation, enlargement of the neuronal cell body, shortening 
or abnormal increase and thinning of axonal length, vacuole formation, and selective neurotoxicity.

\section{IS C USS I O N}

Since January 2020, SARS-CoV-2 outbreaks have been documented globally. The speed at which the pandemic spread has emphasized inherent deficiencies in national emergency preparedness and response protocols for most countries. Mounting evidence points to SARS-CoV-2 being highly contagious and easily transmittable via droplets and fomites, and has been associated with ARDS in hospitalized patients. ${ }^{4}$ Anosmia and hypogeusia, the inability or decreased ability to smell and taste, has been reported as common and specific symptoms in the SARS-CoV-2 infected. Most patients show no other symptoms and regain their smell and taste.9,14

A study of 417 mild to moderate COVID-19 patients from 12 European hospitals reported that $85.6 \%$ and $88.0 \%$ of patients described olfactory and gustatory dysfunctions, respectively, and a significant association existed between both disorders $(p<0.001) .{ }^{8}$ Olfactory dysfunction appeared before other symptoms in $11.8 \%$ of cases. Numerous reports describe anosmia with incident rates varying between $41 \%$ to over $80 \%$, depending on the populations studied. ${ }^{15,16}$ Nevertheless, the severity of smell dysfunction varies widely among patients ${ }^{17}$, with many illustrating a reduction in taste and chemesthetic sensing. ${ }^{18}$

One objective of the present study was to explore whether brain neurons, which are constantly going through neurogenesis, were primary targets of SARS $\mathrm{CoV}-2$. Neurogenesis in the adult human brain has been confirmed in two regions: the subventricular zone (SVZ) of the anterior lateral ventricles, the site of origin for $\mathrm{OB}$ neurons, and the dentate gyrus (DG) of the hippocampus, the region of a human brain that is involved in learning and memory. In the SVZ, progenitor cells migrate to the $\mathrm{OB}$, where they terminally differentiate into neurons and serve the role of sensing odors. In contrast, DG cells divide along the sub-granular zone and migrate into the granule cell layer before terminally differentiating into granule cells. Since none of the progenitor neuronal cell lines were permissive to the SARS$\mathrm{CoV}-2$ virus, it is unlikely that they represent targets of SARS-CoV-2. However, upon RA-induced differentiation, one cell line, and CRL-127 expressed a low degree of permissiveness to the virus.

Our studies also examined the entry mechanism of the virus. RT-PCR and IFA positive presence of the virus were correlated with the degree of expression of serine protease, TMPRSS2. The SARS$\mathrm{CoV}-2$ comprises four main structural proteins: spike $(S)$, envelope (E), membrane glycoproteins, and a nucleocapsid. The $S$ protein is a transmembrane protein located on the viral surface and enables binding of E proteins to host cells by attraction to ACE2. ${ }^{19} S$ glycoprotein comprises two subunits: $S_{1}$, which binds to the host cell receptor, and $S_{2}$, which fuses the viral and host cell membranes. ${ }^{19,20}$ After fusion, TMPRSS2 cleaves the ACE2 and activates the $S$ proteins to facilitate virus entry into the host cell. ${ }^{20,21}$ Without TMPRSS2, the virus cannot enter the cell, which has prompted some to suggest that TMPRSS2 might represent an intervention point for SARS-CoV-2 treatment. ${ }^{22,23}$ We also observed low expression of ACE2 for all the neuronal cell lines utilized in this investigation. However, none of the neuronal cell lines expressing low ACE2 were permissive to SARS-CoV-2. We believe that this may be due to the absence of ACE2 protein on the neuronal surface or that permissiveness may require minimal ACE2 receptor density on the cellular surface for the entry of the virus. This notion may require further study.

The importance of ACE2 receptors has been thoroughly investigated, but without the engagement of TMPRSS2, the virus cannot enter target cells.

In some studies the investigators did not identify ACE2 receptors. This absence of ACE2 receptors, with the clear evidence of olfactory neuronal damage, is explained by indirect entry of COVID-19. ${ }^{24}$ However, the recent data of Klingenstein et al, ${ }^{25}$ has shown expression of both ACE2 and TMPRSS2. These authors demonstrated that ACE2 is located in the sustentacular and the glandular cells in the olfactory epithelium and the basal, glandular, and epithelial cells of the respiratory epithelium. They also showed TMPRSS2 in the sustentacular and the glandular cells of the olfactory epithelium, providing basic anatomical evidence for the expression of ACE2 and TMPRSS2 in the human nose, olfactory epithelium, and OB. Fodoulian et al, ${ }^{26}$ have also shown substantial expression of the genes coding for the virus receptor ACE2 and TMPRSS2, which act as a virus internalization enhancer. They carried out a human olfactory single-cell RNA-seq dataset 
and determined that sustentacular cells, which maintain the integrity of olfactory sensory neurons, express ACE2 and TMPRSS2. ACE2 protein was highly expressed in a subset of sustentacular cells in human and mouse olfactory tissues. In addition to some contradictions regarding the presence or absence of ACE2 receptors on olfactory neurons, it should be noted that an overwhelming body of evidence confirms the infection of olfactory neurons, including the duration of loss of smell (anosmia or dystonia) in a significant number of patients, changes within the $\mathrm{OB}$ on magnetic resonance imaging, identification of viral particles within the $\mathrm{OB}$ in post-mortem specimens, and the inverse association between severity of COVID-19 and the prevalence of olfactory loss ${ }^{27}$ exists. A recent study has described the expression of ACE2 receptors on glial cells neurons and skeletal muscle cells. $^{28}$ The authors also reported several postCOVID-19 manifestations, including neurological symptoms in $31.37 \%$ of patients (the most common neurological symptom was headache in $\sim 20 \%$ of the patients).

It should be noted that we have analyzed the permissiveness of SARS-CoV-2 in vitro. In vivo olfaction is a complex process, and the $\mathrm{OB}$ is a multilayer structure where odor information is relayed to the central nervous system (CNS) in sequential stages, and the TCs, OB glomeruli, and MCs interact in a highly coordinated fashion. In our experimental model, we tested a monolayer of olfactory neuronal cell lines. Therefore, no precise mechanisms can be discerned. Humans have between 10-20 million ORNs. It is unlikely that all olfactory neurons will die immediately after COVID-19 infection in every infected individual. As illustrated by Altunisik et $\mathrm{al},{ }^{28}$ a small number of infected individuals suffer from complete anosmia. Butowt and von Bartheld ${ }^{29}$ determined a significant difference in the prevalence of loss of smell in patients in different populations. For example, they showed that in East Asians the prevalence of anosmia was around 22\%, whereas in Westerners, it was $48 \%$. Variations $S$ protein in SARS-CoV-2 also play an important role since not all variants are expected to have the same affinity for ACE2. The replication rate of the viral variations in other proteins in the virus also plays an important role since all the virus variants are not replicating at the same rate. And, finally, the initial viral load may all impact the loss of smell.
These authors have noted that olfactory neurons do not express ACE2 receptors, which is now clearly refuted by more recent reports. ${ }^{24,25,27}$ They argue that if SARS-CoV-2 is cytopathic to olfactory neurons, then why do some individuals regain their sense of smell quickly and others take longer? However, no one has clearly shown that all the olfactory neurons are killed by the virus. The genetic variations in the $S$ proteins ACE2 variations within the ACE2 receptors, and the complex six-layered structure may play an important role in protecting the $\mathrm{OB}$ from complete destruction. Also, olfaction is a highly complex process involving six layers just in the $\mathrm{OB}$, and we are not aware if $\mathrm{ACE} 2$ receptors are expressed in all six layers of olfactory neurons. The preceding authors argue that replacing olfactory neurons takes eight to 10 days and an additional five days for cilia maturation, but the recovery of smell in SARS-CoV-2 takes about a week. This suggests that COVID-19 infection does not necessarily kill all the olfactory neurons but, SPEs on OB most likely injure a small part of neurons in OB. It should be noted that we are unaware at what stage of differentiation olfactory neurons express ACE2 receptors. If this occurs at the terminal stage of differentiation that it would explain why some people regain their smell after a week since it will take only three to five days for the cilia to recover. There are still many unknowns in the mystery of anosmia and dysnomia. For example, we do not know if the organization of odorant sensory neurons (OSNs) is affected. The axons of OSNs expressing the same odorant receptors converge onto the same glomerulus at the $\mathrm{OB}$ throughout the adult neurogenesis. Does the SARS-CoV-2 infection disturb the precise locations of convergence after viral-induced SPEs?

As mentioned above, a significant number of COVID-19 infected patients exhibit several postCOVID-19 adverse effects, including muscle pain, fatigue, memory loss, and headache. ${ }^{27,30-32} \mathrm{We}$ wanted to know if neuronal differentiation plays any role in increasing the permissiveness of the virus. Therefore, RA-induced differentiation was carried out to address this question. Our results suggest that in most of the cell lines, partial differentiation does not appear to play any role in increasing the permissiveness of the virus. Only in one cell line (i.e., CRL-127) a slight upregulation of ACE2 was detected such that our results remain inconclusive regarding this question. 
Even though several reports describe severe neurological impacts of COVID-19 patients, ${ }^{33-35}$ our current understanding of how the virus disseminates and migrates into the CNS remains incomplete. However, recent animal models have shed some light on the probable route for viral invasion of the CNS. The mouse ACE2 structure is different from the human ACE2, but a transgenic mouse model, where human ACE2 coding sequences were introduced into wild-type mice under the control of the human cytokeratin 18 (K18) promoter, has revealed interesting results. When K18-hACE2 transgenic mice were infected with SARS-CoV-2, the infection rapidly spread to the alveoli and then, remarkably, spread to subcortical and cortical regions of the mouse brain via the olfactory route. ${ }^{36}$ This model suggests the main entry of SARS- $\mathrm{CoV}$ to the $\mathrm{CNS}$ is via the $\mathrm{OB},{ }^{36}$ and this has been elegantly demonstrated for SARS-CoV infections in ACE2 transgenic mice. ${ }^{37}$

The limitation of the present study is that we have utilized olfactory cell lines rather than human subjects (which would be unethical). Furthermore, we have only used two olfactory neuronal cell lines and a geographically restricted viral strain. While there are infinite differences between the vivo human brain and $\mathrm{OB}$ and the vitro state as presented herein, despite this limitation, we believe that a clear picture of the permissiveness of olfactory neurons is demonstrated, without a gender bias, and suggests a prospective mechanism for SARS-CoV-2based anosmia.

\section{CONCLUSION}

Our findings strengthen the reported association of SARS-CoV-2 infection with loss of smell in individuals infected with the virus. Our results suggest that olfactory neurons originating from both genders were highly permissive to SARS-CoV-2 infection. Moreover, there were no differences in permissiveness to infection between male and female neurons. The infrequent susceptibility of other undifferentiated or partially differentiated neurons suggest it would be unlikely that SARS-CoV-2 infects other mature human brain neurons since, after birth, they have mostly completed neurogenesis. Our studies confirm the neurotropism of the SARS-CoV-2 to olfactory neurons. Preliminary observations indicate that the TMPRSS2 receptor mediates viral entry.

\section{Disclosure}

The authors declared no conflicts of interest. No funding was received for this study.

\section{R E F E R E N C E S}

1. Spreeuwenberg P, Kroneman M, Paget J. Reassessing the global mortality burden of the 1918 influenza pandemic. Am J Epidemiol 2018 Dec;187(12):2561-2567.

2. Johnson NP, Mueller J. Updating the accounts: global mortality of the 1918-1920 "Spanish" influenza pandemic. Bull Hist Med 2002;76(1):105-115.

3. Coronaviridae Study Group of the International Committee on Taxonomy of Viruses. The species Severe acute respiratory syndrome-related coronavirus: classifying 2019-nCoV and naming it SARS-CoV-2. Nat Microbiol 2020 Apr;5(4):536-544.

4. Rothan HA, Byrareddy SN. The epidemiology and pathogenesis of coronavirus disease (COVID-19) outbreak. J Autoimmun 2020 May;109:102433.

5. CDC. (2021). Symptoms of coronavirus. [cited ]. Available from: http://www.cdc.gov/coronavirus/2019ncov/ symptoms -testing/symptoms.html accessed $01 / 22 / 2021$.

6. Spinney L. (2018). Pale rider: the Spanish flu of 1918 and how it changed the world. Johnathan Cape, London, UK.

7. Burgos-Blasco B, Güemes-Villahoz N, Donate-Lopez J, Vidal-Villegas B, García-Feijóo J. Optic nerve analysis in COVID-19 patients. J Med Virol 2021;93(1)-190-191.

8. Lechien JR, Chiesa-Estomba CM, De Siati DR, Horoi M, Le Bon SD, Rodriguez A, et al. Olfactory and gustatory dysfunctions as a clinical presentation of mild-tomoderate forms of the coronavirus disease (COVID-19): a multicenter European study. Eur Arch Otorhinolaryngol 2020 Aug;277(8):2251-2261.

9. Meng X, Deng Y, Dai Z, Meng Z. COVID-19 and anosmia: A review based on up-to-date knowledge. Am J Otolaryngol 2020 Sep - Oct;41(5):102581.

10. Klopfenstein T, Kadiane-Oussou NJ, Toko L, Royer PY, Lepiller Q, Gendrin V. Features of anosmia in COVID-19. Med Mal Infect 2020;50(5):436-439.

11. Bilinska K, Butowt R. Anosmia in COVID-19: A bumpy road to establishing a cellular mechanism. ACS Chem Neurosci 2020 Aug;11(15):2152-2155.

12. Hughes BW, Addanki KC, Sriskanda AN, McLean E, Bagasra O. Infectivity of immature neurons to Zika virus: A link to congenital Zika syndrome. EBioMedicine 2016 Aug; 10:65-70.

13. Interim Laboratory Biosafety Guidelines for Handling and Processing Specimens Associated with Coronavirus Disease 2019 (COVID-19). [cited 2021 Feb 26]. Available from: https://www.cdc.gov/coronavirus/2019-ncov/lab/ lab-biosafety-guidelines.html.

14. Altin F, Cingi C, Uzun T, Bal C. Olfactory and gustatory abnormalities in COVID-19 cases. Eur Arch Otorhinolaryngol 2020 Oct;277(10):2775-2781.

15. Klinger VT, Tenório Lins Carnaúba A, Wanderley Rocha K, Cristina Lyra de Andrade K, Ferreira, SMS, Menezes P. Olfactory and taste disorders in COVID-19: A systematic review. Braz J Otorhinolaryngol 2020 Nov-Dec;86(6): 781-792.

16. Mehraeen E, Behnezhad F, Salehi MA, Noori T, Harandi $\mathrm{H}$, Alinaghi SA. Olfactory and gustatory dysfunctions due to the coronavirus disease (COVID-19): a review of current evidence. Eur Arch Otorhinolaryngol 2021 Feb;278(2):307-312.

17. Moein ST, Hashemian SM, Mansourafshar B, KhorramTousi A, Tabarsi P, Doty RL. Smell dysfunction: biomarker for COVID-19. Int Forum Allergy Rhinol 2020 Aug;10(8):944-950.

18. Parma V, Ohla K, Veldhuizen MG, Niv MY, Kelly CE, Bakke AJ, et al; GCCR Group Author. More than 
smell-COVID-19 is associated with severe impairment of smell, taste, and chemesthesis. Chem Senses 2020 Oct;45(7):609-622.

19. Walls AC, Park YJ, Tortorici MA, Wall A, McGuire AT, Veesler D. Structure, function, and antigenicity of the SARS-CoV-2 spike glycoprotein. Cell 2020 Apr;181(2):281-292.e6.

20. Tortorici MA, Veesler D. Structural insights into coronavirus entry. Adv Virus Res 2019;105:93-116.

21. Rabi FA, Al Zoubi MS, Kasasbeh GA, Salameh DM, AlNasser AD. SARS-CoV-2 and coronavirus disease 2019: what we know so far. Pathogens 2020 Mar;9(3):231.

22. Rahman N, Basharat Z, Yousuf M, Castaldo G, Rastrelli $\mathrm{L}$, Khan $\mathrm{H}$. Virtual screening of natural products against type II transmembrane serine protease (TMPRSS2), the priming agent of coronavirus 2 (SARS-CoV-2). Molecules 2020 May;25(10):2271.

23. Hoffmann M, Kleine-Weber H, Schroeder S, Krüger N, Herrler T, Erichsen S, et al. SARS-CoV-2 cell entry depends on ACE2 and TMPRSS2 and is blocked by a clinically proven protease inhibitor. Cell 2020 Apr;181(2):271-280.e8.

24. Brann DH, Tsukahara T, Weinreb C, Lipovsek M, Van den Berge K, Gong B, et al. Non-neuronal expression of SARS-CoV-2 entry genes in the olfactory system suggests mechanisms underlying COVID-19-associated anosmia. Sci Adv 2020 Jul;6(31):eabc5801.

25. Klingenstein M, Klingenstein S, Neckel PH, Mack AF, Wagner AP, Kleger A, et al. Evidence of SARS-CoV2 entry protein ACE2 in the human nose and olfactory bulb. Cells Tissues Organs 2020;209(4-6):155-164.

26. Fodoulian L, Tuberosa J, Rossier D, Boillat M, Kan C, Pauli $\mathrm{V}$, et al. (2020). SARS-CoV-2 receptors and entry genes are expressed in the human olfactory neuroepithelium and brain. iScience 2020;23(12):101839.

27. Hopkins C, Lechien JR, Saussez S. More that ACE2? NRP1 may play a central role in the underlying pathophysiological mechanism of olfactory dysfunction in COVID-19 and its association with enhanced survival. Med Hypotheses 2021 Jan;146:110406.
28. Altunisik E, Sayiner HS, Aksoz S, Cil E, Ozgenc G. Neurological symptoms in COVID-19 patients. Bratisl Lek Listy 2021;122(1):39-44.

29. Butowt R, von Bartheld CS. Anosmia in COVID-19: Underlying mechanisms and assessment of an olfactory route to brain infection. Neuroscientist 2020 Sep;11:1073858420956905.

30. Hu J, Jolkkonen J, Zhao C. Neurotropism of SARS$\mathrm{CoV}-2$ and its neuropathological alterations: Similarities with other coronaviruses. Neurosci Biobehav Rev 2020 Dec;119:184-193.

31. Pellegrini L, Albecka A, Mallery DL, Kellner MJ, Paul D, Carter AP, et al. SARS-CoV-2 infects the brain choroid plexus and disrupts the blood-CSF barrier in human brain organoids. Cell Stem Cell 2020 Dec;27(6):951-961.e5.

32. Uversky VN, Elrashdy F, Aljadawi A, Ali SM, Khan RH, Redwan EM. Severe acute respiratory syndrome coronavirus 2 infection reaches the human nervous system: How? J Neurosci Res 2021 Mar;99(3):750-777.

33. Asadi-Pooya AA, Simani L. Central nervous system manifestations of COVID-19: A systematic review. J Neurol Sci 2020 Jun;413:116832.

34. Baig AM. Neurological manifestations in COVID-19 caused by SARS-CoV-2. CNS Neurosci Ther 2020 May;26(5):499-501.

35. Wu Y, Xu X, Chen Z, Duan J, Hashimoto K, Yang L, et al. Nervous system involvement after infection with COVID-19 and other coronaviruses. Brain Behav Immun 2020 Jul;87:18-22.

36. McCray PB Jr, Pewe L, Wohlford-Lenane C, Hickey M, Manzel L, Shi L, et al. Lethal infection of K18-hACE2 mice infected with severe acute respiratory syndrome coronavirus. J Virol 2007 Jan;81(2):813-821.

37. Netland J, Meyerholz DK, Moore S, Cassell M, Perlman S. Severe acute respiratory syndrome coronavirus infection causes neuronal death in the absence of encephalitis in mice transgenic for human ACE2. J Virol 2008 Aug;82(15):7264-7275. 